\title{
Role of frozen section analysis of testicular/paratesticular fibrous pseudotumours: a five-case experience
}

\author{
Jennifer Gordetsky, MD; $;^{*}$ Jennifer Findeis-Hosey, MD; ${ }^{*}$ Erdal Erturk, MD; ${ }^{\dagger}$ Edward M. Messing, MD; ${ }^{\dagger}$ \\ Jorge L. Yao, MD; * Hiroshi Miyamoto, MD, PhD*
}

*Department of Pathology \& Laboratory Medicine, University of Rochester Medical Center, Rochester, NY; †Department of Urology, University of Rochester Medical Center, Rochester, New York, USA

Cite as: Can Urol Assoc J 2011;5(4):e47-e51; D01:10.5489/cuaj.10144

\section{Abstract}

Background: Fibrous pseudotumours of the testicular and paratesticular tissues are fibroinflammatory reactive lesions that can clinically mimic neoplasms. Very little is known about the role of frozen section analysis (FSA) for these lesions in terms of intraoperative surgical management.

Methods: We recently experienced 5 patients with testicular/paratesticular fibrous pseudotumours in whom frozen sections were used to demonstrate its non-neoplastic nature prior to the decision for radical surgery.

Results: In 2 cases, FSA resulted in testicular-sparing surgery. In contrast, the remaining 3 cases ultimately underwent radical orchiectomy, due to questionable viability of the testicle involved by inflammatory/infiltrative lesions and in 1 case a slight possibility of lymphoproliferative malignancy.

Conclusion: Urologists should be aware of this entity and its gross features, such as firm masses and diffuse fibrous proliferation encasing the testicle to help determine intraoperative management. In select cases, intraoperative FSA is helpful in obviating radical orchiectomy.

\section{Introduction}

Fibrous pseudotumours of testicular and paratesticular tissues are believed to be reactive non-neoplastic fibroinflammatory lesions often associated with local trauma, hydrocele or infection. ${ }^{1,2}$ Grossly, fibrous pseudotumours are nodular lesions localized to the testicular tunics, epididymis, paratesticular tissues or spermatic cord. Histologically, they consist of dense fibrosis with a mixed inflammatory cell infiltrate and granulation tissue..$^{1-5}$ Rarely, fibrous pseudotumours may consist of a diffuse fibroinflammatory proliferation of the paratesticular/testicular soft tissues which encase the testis, more specifically known as fibromatous periorchitis.,

Fibrous pseudotumours of testicular and paratesticular tissues are especially significant in that clinical suspicion may lead to a testicular neoplasm as the primary differ- ential diagnosis, thus resulting in radical orchiectomy as the primary treatment option. The utility of frozen section analysis (FSA) in intraoperative surgical management, especially obviation of unnecessary radical surgery, has never been properly investigated. We report 5 cases of testicular/ paratesticular fibrous pseudotumours that were clinically suspicious for testicular neoplasms. Intraoperative frozen sections were used to demonstrate the non-neoplastic nature of these lesions with 2 cases resulting in a testicular-sparing surgery. We specifically discuss the significance of FSA for assisting conservative surgery in patients with testicular/paratesticular fibrous pseudotumours.

We summarize the clinicopathologic findings of these 5 cases of testicular/paratesticular fibrous pseudotumour (Table 1).

\section{Case 1}

\section{Clinical findings}

A 37-year-old male with a remote history of vasectomy presented with several weeks of right testicular pain. Physical examination of the right testicle revealed a hydrocele with an otherwise normal appearing testis, which was confirmed with Duplex ultrasonography. The patient was scheduled for a hydrocele repair. At the time of surgery, 4 weeks after initial presentation, physical examination under anesthesia demonstrated the absence of a palpable hydrocele with the right testicle being diffusely enlarged and firm. Intraoperatively, there were signs of significant periorchitis with adhesions of the testicle to the scrotal wall and a hematocele. A biopsy was sent for frozen section, which confirmed fibrosis and chronic inflammation with no malignancy identified. Although there was high suspicion for nodular periorchitis, the testicle was questionably viable and the patient had been suffering from severe, chronic testicular pain unrelieved by antibiotics. After discussion with the family, a radical orchiectomy was performed. 


\begin{tabular}{|c|c|c|c|c|c|c|}
\hline $\begin{array}{l}\text { Case } \\
\text { no. }\end{array}$ & $\begin{array}{l}\text { Age, } \\
\text { years }\end{array}$ & Presentation & Frozen section diagnosis & $\begin{array}{l}\text { Histological } \\
\text { subtype }^{5}\end{array}$ & Treatment & $\begin{array}{l}\text { Reason for } \\
\text { orchiectomy }\end{array}$ \\
\hline 1 & 37 & $\mathrm{R}$ testicular pain & $\begin{array}{c}\text { Fibrosis, chronic } \\
\text { inflammation, hemorrhage }\end{array}$ & Myofibroblastic & R Orchiectomy & $\begin{array}{c}\text { Questionable } \\
\text { testicular viability, } \\
\text { severe chronic pain }\end{array}$ \\
\hline 2 & 50 & History of R hydrocele & Dense fibrosis & Plaque-like & R Orchiectomy & $\begin{array}{l}\text { Questionable } \\
\text { testicular function, } \\
\text { Infiltrative lesion }\end{array}$ \\
\hline 3 & 69 & $\begin{array}{c}\text { B painless testicular } \\
\text { masses }\end{array}$ & $\begin{array}{c}\text { Dense fibrosis, } \\
\text { lymphocytic proliferation }\end{array}$ & $\begin{array}{l}\text { Inflammatory } \\
\text { sclerotic }\end{array}$ & R Orchiectomy & $\begin{array}{c}\text { Possibility of } \\
\text { Iymphoproliferative } \\
\text { malignancy }\end{array}$ \\
\hline 4 & 30 & $\mathrm{~L}$ testicular painless mass & $\begin{array}{l}\text { Inflammatory fibrous } \\
\text { pseudotumour }\end{array}$ & $\begin{array}{l}\text { Inflammatory } \\
\text { sclerotic }\end{array}$ & Excision & Testicular sparing \\
\hline 5 & 46 & $\mathrm{R}$ testicular pain & Fibrosis, edema & Plaque-like & Excision & Testicular sparing \\
\hline
\end{tabular}

R: right; L: left; B: bilateral.

\section{Pathological findings}

Frozen section examination was performed on 2 specimens: a $1.0 \times 0.5 \times 0.4-\mathrm{cm}$ tan-brown soft tissue fragment and a $1.5 \times 0.8 \times 0.5-\mathrm{cm}$ pink and extensively cauterized soft tissue fragment. Microscopic examination of these biopsies at the time of frozen section demonstrated fibrosis, a dense lymphocytic infiltrate, and hemorrhage, with no malignancy identified (Fig. 1, part A).

A final 62-g right orchiectomy specimen was received with a $7.0 \times 4.0 \times 3.5-\mathrm{cm}$ partially disrupted testicle with an attached spermatic cord, $3.0 \mathrm{~cm}$ long and $1.5 \mathrm{~cm}$ in diameter. Gross examination of the testicle demonstrated extensive adhesions of the external surface with a fixed parietal and visceral tunica vaginalis (Fig. 1, part B). There was a $0.7 \times 0.5 \times 0.5-\mathrm{cm}$ well-circumscribed, firm gray nodule in the testicular parenchyma along the convex surface immediately adjacent to the tunica. The epididymis grossly appeared to have been replaced by grey-white fibrousappearing tissue with large areas of hemorrhage.

Microscopic examination of the right orchiectomy specimen demonstrated a thick fibrous band with associated hemorrhage in the regions grossly identified as the parenchymal nodule and grossly replaced epididymis (Fig.1, parts C and D). The fibrous band consisted of fascicles of spindle cells with large round to oval nuclei with prominent nucleoli and nuclear clearing. These spindle cells displayed basophilic cytoplasm and indistinct cell borders. The spindle cells were in an eosinophilic background of hyalinized collagenous stroma with admixed hemorrhage and mixed inflammatory infiltrate. The fibrous band did not microscopically invade either the seminiferous tubules or the epididymis, rather it remained confined to the tunica albuginea and tunica vaginalis.

\section{Case 2}

\section{Clinical findings}

A 50-year-old male presented with long-standing history of right hydrocele and a family history of testicular cancer. The patient had no history of scrotal surgery, trauma or infection. The lower pole of the right testicle was diffusely firm and irregular. Ultrasound revealed an inhomogeneous right testicle with microlithiasis. Clinically, the mass was suspicious for a testicular malignancy and the patient was scheduled for a radical orchiectomy. Three excisional biopsies, from separate areas of the right testicle, were sent for frozen section. No seminiferous tubules were identified and each biopsy consisted of dense fibrocollagenous tissue. Although confirmed to be benign by FSA, the fibrous lesions were infiltrative and the testicle was questionably functional. Thus, a radical orchiectomy was performed.

\section{Pathological findings}

Frozen section examination was performed on 3 grey-white rubbery fragments of tissue, ranging from 1.0 to $1.2 \mathrm{~cm}$. Microscopic examination of these biopsies at the time of frozen section demonstrated dense fibrocollagenous tissue and scattered lymphocytes (Fig. 2, part A).

A final 73-g right orchiectomy specimen was received with a $4.0 \times 3.5 \times 3.0-\mathrm{cm}$ partially disrupted testicle with attached spermatic cord $18.0 \mathrm{~cm}$ long and $1.8 \mathrm{~cm}$ in diameter. Gross examination of the testicle demonstrated a $3.6 \times 3.2 \times 3.0$ $\mathrm{cm}$ ovoid, rubbery grey-white area replacing about $75 \%$ of the testicular parenchyma. Microscopic examination of the right orchiectomy specimen demonstrated diffuse fibrosis and testicular atrophy with minimal chronic inflammation (Fig. 2, part B). 


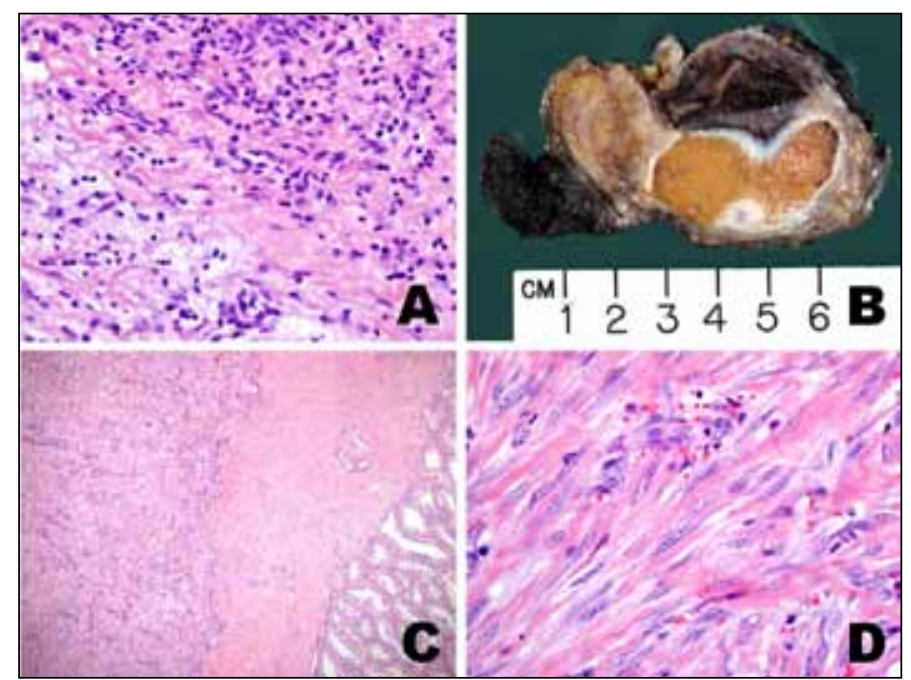

Fig. 1. Case 1. (A) Frozen section examination of right testicular biopsy demonstrating fibrosis and chronic inflammation (hematoxylin and eosin [H\&E], original magnification $\times 100$ ). (B) Gross appearance of right orchiectomy specimen demonstrating a firm, well-circumscribed nodule within testicular parenchyma and replacement of the epididymis with fibrous and hemorrhagic tissue. (C) Right orchiectomy specimen demonstrating testicular nodule and fibrous peri-testicular band adjacent to unremarkable seminiferous tubules $(H \& E$, original magnification $\times 40)$. (D) Right orchiectomy specimen demonstrating testicular nodule and peri-testicular band composed of fascicles of bland spindle cells in an eosinophilic background of hyalinized collagenous stroma with admixed hemorrhage ( $H \& E$, original magnification $\times 400)$.

\section{Case 3}

\section{Clinical findings}

A 69-year-old male presented with bilateral testicular painless masses; the mass on the right side was a year old and the left side was a month old. The patient had no history of scrotal surgery, trauma or infection. Testicular ultrasound showed diffusely enlarged testicles with a left intratesticular mass and a right paratesticular mass. The differential diagnosis was a benign inflammatory process versus a lymphoproliferative malignancy. The patient was brought to the operating room for a definitive diagnosis. Frozen sections of the biopsies from right testicle and paratesticular tissue revealed fibrosis with lymphoid proliferation. A lymphoproliferative malignancy could not be completely excluded and a right radical orchiectomy was performed.

\section{Pathological findings}

Frozen section examination was performed on 5 separate pieces of tan-pink soft tissue, ranging from $0.8 \mathrm{~cm}$ to $2.2 \mathrm{~cm}$. Microscopic examination of these biopsies at the time of frozen section demonstrated dense fibrocollagenous tissue with lymphoid aggregates in which lymphoproliferative disorders could not be completely excluded.

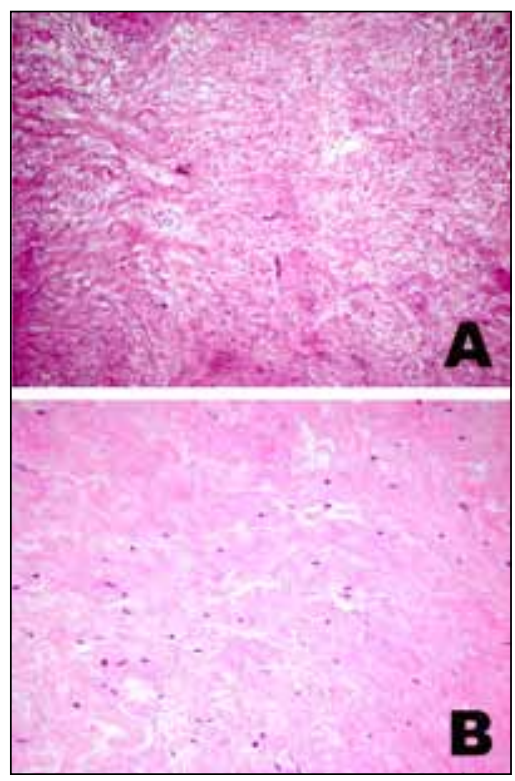

Fig. 2. Case 2. Frozen section examination of right testicular biopsy (A, hematoxylin and eosin $[H \& E]$, original magnification $\times 40$ ) and right orchiectomy specimen $(B, H \& E$, original magnification $\times 200$ ) demonstrating nodular fibrosis and minimal chronic inflammation.

A final 58.5-g orchiectomy specimen was received with a previously opened $7.5 \times 4.0 \times 2.8$ - $\mathrm{cm}$ testis with attached $2.0-\mathrm{cm}$ long and $1.0-\mathrm{cm}$ diameter spermatic cord. Gross examination of the testicle identified a paratesticular $2.0 \times 1.0 \times 0.6$-cm lobulated white-tan mass. A hematocele was present between the testicle and the tunica vaginalis. The testicular parenchyma and spermatic cord were grossly unremarkable. Microscopic examination of the right orchiectomy specimen demonstrated residual dense fibrous tissue containing lymphocytic aggregates and occasional germinal centers, which was unlikely a lymphoma. There was a delicate vasculature in some areas. The fibrous band did not microscopically invade either the seminiferous tubules or the epididymis.

\section{Case 4}

\section{Clinical findings}

A 30-year-old male presented with a new finding of a left testicular painless mass. Duplex ultrasonography showed a $0.5-\mathrm{cm}$ non-calcified solid lesion, which appeared to be arising from the epididymis or paratesticular tissues. The patient had no history of scrotal surgery, trauma or infection. Clinically the mass was suspicious for a paratesticular malignancy and the patient was scheduled for a radical orchiectomy. Intraoperatively, a 0.5 -cm exophytic mass was identified in the cephalad portion of the testicle with an associated hydrocele. Clinical suspicion was that the mass was an old torsed appendix testis that had become fibrotic. The mass was sent for frozen section diagnosis which revealed it to be an inflammatory fibrous pseudotumour. The diagnosis resulted in testicular-sparing surgery. 


\section{Pathological findings}

Frozen section examination was performed on a $0.6 \times 0.6 \times 0.5-\mathrm{cm}$ nodular tan-pink soft tissue fragment. Microscopic examination at the time of frozen section demonstrated dense nodular fibrosis and admixed lymphocytic infiltrates, occasional plasma cells, and rare neutrophils (Fig. 3, part A). An increased capillary network was noted, but no malignancy was identified. The diagnosis was made of inflammatory fibrous pseudotumour. Histology of the frozen section control confirmed the findings (Fig. 3, part B).

\section{Case 5}

\section{Clinical findings}

A 46-year-old male presented with right testicular pain. The patient had no history of scrotal surgery, trauma or infection, but his son had a history of testicular torsion with orchiopexy. Ultrasound showed findings suspicious for intermittent torsion and ischemia, but the presence of a tumour could not be excluded. Testicular exam under anesthesia showed no discrete mass. A slightly irregular firm area on the tunica albuginea was biopsied and was sent for frozen section. This revealed fibrosis with no malignancy and testicular-sparing surgery resulted.

\section{Pathologic findings}

Frozen section examination was performed on a $1.5 \times 0.3 \times 0.1-\mathrm{cm}$ tan-pink, rubbery tissue fragment. Microscopic examination at the time of frozen section demonstrated dense fibrosis and edema without significant inflammatory cell infiltrates or any evidence of malignancy.

\section{Discussion}

It is believed that testicular/paratesticular fibrous pseudotumours are reactive lesions that can involve paratesticular tissues, testicular tunics, epididymis and/or the spermatic cord..$^{1-5} \mathrm{~A}$ recent study showed that, based on 13 cases, fibrous pseudotumour can be histologically subdivided into 3 categories: (1) plaque-like (dense fibrosis without significant inflammation); (2) inflammatory sclerotic (dense fibrosis with significant inflammation); and (3) myofibroblastic (reactive looking, tissue-culture like cells with numerous capillaries and sparse inflammation). ${ }^{5}$ Immunohistochemical analysis in their study showed overlapping features of the profile with variable morphologic patterns, suggesting that testicular/paratesticular fibrous pseudotumour could be the result of several distinct processes. Because stains for anaplastic lymphoma kinase- 1 and $\beta$-catenin were negative in

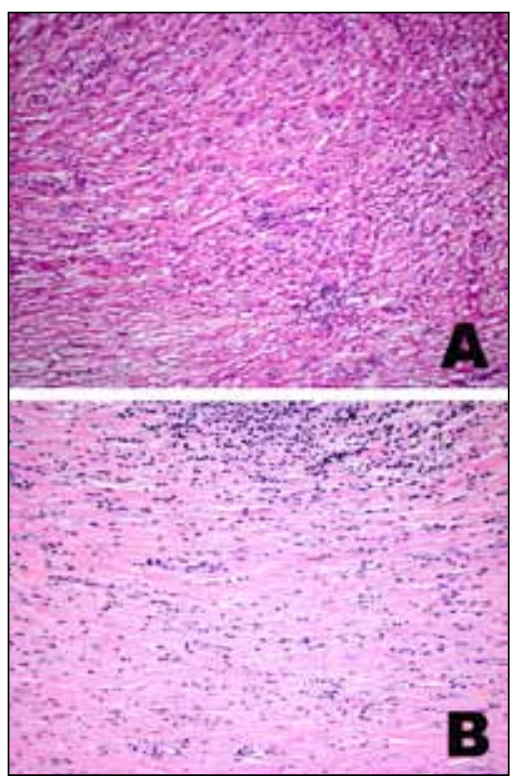

Fig. 3. Case 4. Frozen section examination of right testicular biopsy $(A$, hematoxylin and eosin[H\&E], original magnification $\times 40$ ) and its control stain $(B, H \& E$, original magnification $\times 200$ ) demonstrating dense fibrocollagenous tissue and a mixed inflammatory infiltrate with prominent capillary network.

all the above subtypes, there seemed to be no correlation between testicular/paratesticular fibrous pseudotumour and inflammatory myofibroblastic tumour or fibromatosis seen in other organs. ${ }^{5}$ Historically, fibrous pseudotumours have been referred to by multiple names including fibromatous periorchitis, nonspecific paratesticular fibrosis, nodular fibropseudotumour, reactive periorchitis, fibroma, fibrous pseudotumour, pseudofibromatous periorchitis, proliferative funiculitis and several others. ${ }^{2,5,6}$ However, because some lesions lack inflammatory component and are not nodular, the less specific term "fibrous pseudotumour" was preferred. ${ }^{5}$

Although fibrous pseudotumours are non-neoplastic lesions, many patients will undergo radical orchiectomy for suspicion of malignancy. Considering this process is often localized and occurs in younger males, testicular sparing surgery should be considered a possibility. The diffuse form of fibrous pseudotumour can be extremely difficult to excise and testicular-sparing surgery has rarely been reported in the literature for this lesion. In the current study, we detail 5 cases of testicular/paratesticular fibrous pseudotumour where the use of FSA led to the diagnosis of this reactive, non-neoplastic lesion. Nonetheless, the first, second and third cases underwent orchiectomy. Major reasons for radical surgery included questionable viability of the testicle due to inflammatory and/or infiltrative conditions and inability to definitively rule out a lymphoproliferative malignancy. In the fourth and fifth cases, intraoperative suspicion was for a benign lesion. Diagnosis via frozen section was useful for intraoperative management and conversion from radical orchiectomy to testicular-sparing surgery.

Histologically, the differential diagnosis for testicular/ paratesticular fibrous pseudotumour may include fibrous mesothelioma, neurofibroma, leiomyoma, idiopathic fibromatosis, unclassified sex cord-stromal tumour, angiomyo- 
fibroblastoma, solitary fibrous tumour, leiomyosarcoma, fibrosarcoma and malignant fibrous histiocytoma. ${ }^{1,2,6}$ It is usually possible to distinguish between these entities via the morphological appearance of the lesion, in conjunction with immunohistochemical stains and the presence or absence of infiltration into the surrounding tissue. However, at the time of intraoperative FSA, it may be difficult to make a definitive diagnosis of fibrous pseudotumour on a limited specimen. Indeed, in 4 of the 5 cases (cases 1, 2, 3, and 5), diagnoses made by general surgical pathologists were rather descriptive. Furthermore, despite the frozen section diagnosis describing a definitive process in two cases (cases 1 and 2 ), orchiectomy was ultimately chosen. Urologists should be aware of this entity as reactive in nature and its variable gross findings including firm mass(es) and diffuse fibrous proliferation encasing the testicle. In select cases, intraoperative FSA for testicular/paratesticular fibrous pseudotumour may play a significant role in obviating radical orchiectomy.
This paper has been peer-reviewed.

\section{References}

1. Tannenbaum M, Madden JF (eds.). Diagnostic Atlas of Genitourinary Pathology. Churchill Livingstone, New York, 2005

2. Bostwick DG, Cheng L (eds.). Urological Surgical Pathology Expert Consult. Mosby, St. Louis, 2008.

3. White WM, Hilsenbeck J, Waters WB. Fibromatous periorchitis of testis. Urology 2006;67:623.e15-6.

4. Seethala RR, Tirkes AT, Weinstein $S$, et al. Diffuse fibrous pseudotumour of the testicular tunics associated with an inflamed hydrocele. Arch Pathol Lab Med 2003;127:742-4.

5. Miyamoto H, Montgomery EA, Epstein Jl. Paratesticular fibrous pseudotumour: A morphologic and immunohistochemical study of 13 cases. Am J Surg Pathol 2010;34:569-74.

6. Jones MA, Young RH, Scully RE. Benign fibromatous tumours of the testis and paratesticular region: A report of 9 cases with a proposed classification of fibromatous tumours and tumour-like lesions. Am J Surg Pathol 1997;21:296-305.

Correspondence: Dr. Hiroshi Miyamoto, Department of Pathology \& Laboratory Medicine, University of Rochester Medical Center, 601 Elmwood Avenue, Box 626, Rochester, NY 14642; fax: 585273-3637; hiroshi_miyamoto@urmc.rochester.edu

Competing interests: None declared. 